\title{
The Role of MOOCs in the Learning of Languages: Lessons From a Beginners' English Course
}

\author{
RuBÉN CHACÓN-BELTRÁN \\ Universidad Nacional de Educación a Distancia (UNED)
}

Received: 17 November 2015/ Accepted: 14 February 2017

ISSN: $1697-7467$

\begin{abstract}
This paper begins by analysing the features of MOOCs - massive open online courses which offer innovative methodological possibilities for the distance teaching and learning of languages. A study with a large cohort of students enrolled in two separate editions of a beginners' English course was carried out. The results are analysed both quantitatively and qualitatively and conclusions pertinent to the MOOC teaching and learning paradigm are discussed. The teaching and learning experience in a MOOC with high levels of student participation and acceptance is described and some methodological support for teachers and researchers thinking of using this teaching methodology is offered.

Keywords: MOOC, language learning, vocabulary learning, learner autonomy, scaffolding

\section{El papel de los MOOCs en el aprendizaje de lenguas: revelaciones de un curso de inglés} para principiantes

RESUMEN: Este artículo comienza analizando las características distintivas de los nuevos cursos MOOC, cursos masivos en abierto y online, que siguen una metodología novedosa por su potencial para la enseñanza/aprendizaje de idiomas de forma autodirigida y a distancia. Se describe un estudio con un grupo numeroso de estudiantes en dos ediciones de un curso de iniciación para el aprendizaje del inglés como Lengua Extranjera. Seguidamente se han llevado a cabo sendos análisis cualitativo y cuantitativo de los resultados obtenidos. Se parte de la experiencia de un curso con una alta aceptación para indagar en las características que debe tener de forma genérica un MOOC y proporcionar consejos que puedan resultar de interés para otros docentes y/o investigadores.
\end{abstract}

Palabras clave: MOOC, aprendizaje de lenguas, aprendizaje de vocabulario, autonomía en el aprendizaje, andamiaje.

\section{INTRODUCTION}

In the last few years, in the area of online teaching and learning a new technologically innovative methodological approach has come into play with significant acceptance in different areas of study, namely, MOOCs (Massive Online Open Courses). MOOCs have consolidated as a means for instruction in universities such as Princeton, Brown, Columbia and Duke (Pappano, 2012). They were originally introduced by Stephen Downes and George Siemens (de Waard, Koutropoulos, Özdamar Keskin, Abajian, Hogue \& Rodriguez, 2011) but their use has spread rapidly and this teaching and learning tool has been adopted and adapted by public and private teaching institutions all over the world. MOOCs generally 
have three distinctive features: (a) they are Internet-based courses containing audiovisual teaching/learning material that are meant to be used totally online, (b) they are free, (c) they are massive, that is, they have been conceived so that huge numbers of users can be studying them simultaneously without need of personalized teacher assistance. This last aspect (the fact that they are massive) constitutes one of the most distinctive features of MOOCs and as a result of crowdsourcing ${ }^{1}$ they represent an innovative teaching and learning methodology. Collaboration and team work among course participants is an important course component (Clarà \& Barberà, 2013) and compensates for the lack of an instructor's personalised assistance. Careful course design and implementation is obviously needed, with content adequately sequenced and graded as well as closed activities for course participants that should be easily corrected and commented on by other course members making use of correction rubrics and/or precise correction instructions. In a general sense, crowdsourcing appears as a new way of communicating and connecting with other people with the same interests, independently of other more topical means of communication that are now frequently used among people that know each other such as the telephone or email. This phenomenon is framed within global social movements by means of which in developed societies, it is easy to communicate not only with people that we already know but also with people we meet incidentally through social media such as Twitter, Facebook, Google+, etc. or equivalent tools in the academic world such as Linkedin, Research Gate, etc. A constant flux of information can be perceived, a tendency to share information and knowledge with other people with similar interests, to help and to be helped by others, usually with freely available resources. Some recent works have further analysed the question of connectivism in online learning (Clarà \& Barberà, 2013; Tinmaz, 2012).

MOOCs' teaching and learning methodology, and their further development, cannot be understood if they are not linked to another key concept very much present in recent decades in the field of language teaching and learning. Learner autonomy is an area of study widely researched by authors like Benson (1996; 2007; 2013), Cotterall \& Cohen (2003), Morrison (2014) and Voller \& Benson (1997), among others. The mere action of enrolling on a MOOC implies a high degree of autonomy and personal interest in fostering one's own learning, in addition to computer literacy. Participation and completion of a MOOC requires enough self-discipline to accomplish a demanding task even if course members count on the help of others, either in the form of (a) audiovisual learning materials provided by course designers, (b) the interaction with other course participants, or (c) the assistance of course facilitators ${ }^{2}$.

MOOCs are not a straightforward homogeneous tool that can be clearly defined, with structured components and goals (Baggaley, 2014). Designing a MOOC is a creative piece of work with technological developments suggesting new approaches. Sangrá Morer (2013b), for instance, refers to the difference between cMOOCs and xMOOCs. The former follow the connectivity principles put forward by Siemens, who considers that web-based learning is fostered through the web with contact and relationship between users. While xMOOCs have a simpler structure and follow a more transmission-based approach; that is, they offer

\footnotetext{
${ }^{1}$ Crowdsourcing means that participants in the MOOC also become "active agents" as they are expected to provide feedback on their course companions' work, for instance, using generic feedback sentences previously provided by course designers to assess other participants' activities.
}

${ }^{2}$ Most MOOCs include the figure of a course facilitator; their main task being to take charge of course maintenance, technical assistance and potential pitfalls that may arise. 
an array of resources with self-directed learning activities which are offered to any course participant who wants to use them. In this case, the provision of feedback is automatised and evaluation is accomplished by means of objective tests. It is not, however, the purpose of this article to define MOOC typologies even though it is an area of research that requires further analysis and would certainly be useful for the development of this area of research.

\section{Challenges in mooc design and implementation}

After the initial delight at the great potential of MOOCs in the field of teaching and learning as a new methodology allowing free access to courses for anyone, anywhere in the world, it became clear that the preparation and implementation of these courses, in any area or field of study, also poses some problems or unanswered questions related to issues like funding and sustainability, methodological adequacy, qualification, etc.

With respect to funding and sustainability, although MOOCs are free access courses with free access materials, they need high-quality content and effective technological tools. A possible solution to this issue could be for MOOC design and implementation to be carried out by higher education institutions both in the public and private sectors. Universities are well-situated to develop and make use of MOOCs as adults and young adults are possibly the population sector that can best benefit from them, and it is probably within the aims of these institutions to develop long-lasting teaching programs that will need to be sustainable in the medium or long term, and suitable for social and economic development.

Dellarocas and Van Alstyne (2013) point out that one of the main problems to be tackled by MOOCs is their funding and sustainability; this is another example of how digital disruption has arrived in the field of education as it previously reached the music and the cinema industries, and the world of journalism and travel. Dellarocas and Van Alstyne (2013) analyse a number of possibilities related to who could finance MOOCs and under what premises. One possibility would be that MOOCs were funded by governments as part of their development policy in social and educational areas. This is already happening for instance in the State of California. Another possibility would be that students pay a fee when they enrol on courses. Student purchase of attainment certificates would also be a solution and this is already happening in Coursera, or the UNED in Spain (Chacón-Beltrán, 2014). Another option that also involves students paying a fee, as suggested by Dellarocas and Van Alstyne (2013), could be the use of MOOCs to offer personalised diagnosis on the strong and weak points of student capabilities. These authors also suggest that the students could get tutorial support to reach higher standards or be offered the chance to contact other course participants who would be compatible in various senses thereby allowing them to constitute working teams for better attainment. These last two possibilities, however, create some sort of conflict with the essence of MOOCs in which collaborative work or crowdsourcing is a fundamental component. Another potential source of funds, as Dellarocas and Van Alstyne (2013) suggest, are businesses that can improve staff training and the skillset of their current or future employees by means of MOOCs. MOOCs can even be used to get information on students' capacities and improve hiring methods. They can also be used by companies to improve their workers' skills or training, as initial training or recycling given their flexibility and low costs. The last option would be to find sponsors that could pay the costs; for instance, companies or professional associations that wish to promote themselves from a commercial point of view or as part of their social programs. Universities may also find 
that it is easier and less expensive to create a MOOC than to hire and train a specialist, in much the same way perhaps as the press nowadays syndicates and hires information that will later be transformed into its news.

Other authors, like Paldy (2013), also pose unanswered questions which could be part of research, for instance: how to evaluate students; whether universities should offer certificates; how to compensate course designers; etc. All these questions should be answered one way or the other as the phenomenon of MOOCs seems to be here to stay and may prove to be a revolutionary teaching/learning methodology comparable to the irruption of the Open University teaching programs in the sixties (Paldy, 2013). At the moment, however, there seem to be few descriptive studies that allow us to get to know in detail the accumulated experience of MOOCs, the demographic profile of MOOCs participants as they are offered globally, or their learning achievements. These data are, however, essential if we are to make progress in the creation of a MOOC learning theory.

\section{Moocs in Language teaching AND LeARning}

Competence in more than one language is certainly one of the challenges people living in Europe need to face as it is often seen as a vehicle for economic development in modern societies. The European Union is making big efforts to attain this goal in all member states; one of its goals being that citizens of all member states should be able to communicate in at least two languages apart from their mother tongue (European Commission, 2012: 386). In the Spanish context, huge efforts are being made by the government and educational institutions at all levels to promote and reinforce foreign language learning, particularly English, as a means of economic and social development.

In the last decade we have seen how ICT (Information and Communication Technologies) play an ever more important role in language teaching and learning. From a methodological point of view, MOOCs appear to have great potential for self-directed English language learning as: (a) there is a possibility for the use of audiovisual materials; (b) the use of the Internet allows oral and written interaction between language learners at the same proficiency levels; (c) they favour collaborative learning; (d) they allow language learners to proceed at their own pace, as Severance (2013: 95) says "MOOC students are more interested in learning at their own pace than in sprinting to a degree in as short a time as possible"; (e) they promote learner autonomy; (f) they encourage the sharing of Internet-based resources; (g) they favour empathy and cooperation between students sharing the same interests.

\section{The CASE OF a Beginners' English COURSE}

With the aim of analysing the potential and usefulness of MOOCs in the field of foreign/second language learning, some actions using qualitative and quantitative procedures for demographic data and academic achievement, obtained through the participation in a MOOC for beginners of English as a second language, were undertaken to analyse users' experience. The main aim was to record our own experience as course designers in implementing a large scale course with an unexpectedly high number of participants, offered globally, and also to analyse the participants' experience of it. 
This course $\mathrm{e}^{3}$ was aimed at participants who had never studied English before and who should be able to read short and easy texts in the newspaper, such as news items or advertisements, after 24 hours of study distributed across 8 weeks. The teaching/learning materials used in this project had been recently published by Cambridge University Press and were backed by a solid research background in Corpus Linguistics to identify the most common senses of the most common words used in written English (Lawley, 2010). These words had been grouped after a contrastive analysis with Spanish to facilitate their recognition and learning (Lawley \& Chacón-Beltrán, 2009). The course designers adopted an explicit and self-directed learning approach so that course participants could take advantage of their previous linguistic knowledge in their mother tongue, and the use of free access resources on the Internet such as electronic dictionaries. This was possible because of the sociocultural features of the course participants, i.e., adult learners with extensive knowledge of their mother tongue. Attention was also paid to an adequate and progressive presentation of course contents so that participants were provided with some scaffolding for gradual learning with the help of 15 videos and 9 documents which had been carefully designed by the course designers. They also received precise instructions on how to go on learning English on their own once the MOOC had been completed. Collaborative work by means of crowdsourcing was also an important component in this MOOC as it included follow-up activities that students had to complete and, with the help of generic feedback, evaluate the work of others. There was a P2P (person to person) resource that allowed all the participants to evaluate and be evaluated by their course companions.

The first edition of this course took place early in 2013 on two different platforms, MiriadaX and UNED Abierta. The course under consideration in this article was first published on that occasion but then it was revised and published again in November 2013 only in UNED-Abierta. The data referred to in this article as a "pilot study" corresponds to the first edition of the MOOC in UNED-Abierta and the data referring to the main study comes from the second edition, which took place in November 2013.

\subsection{Pilot Study}

In its first edition in UNED-Abierta, this course was by some distance the most popular of the 19 available with 44,140 inscriptions, followed by another language learning course with 17,240 inscriptions and a third one with 8,325 inscriptions. It should be pointed out that in fact only 26,266 participants actually watched the two-minute-long presentation video recording. Taking this last figure as a start point, $65.15 \%$ of course participants actually finished the course; that is, 14,500 participants which is in fact a very high percentage if we take into account that according to Sangrá Morer (2013) the drop out rate in MOOCs is in general very high and can be placed around 95\%. Indeed, not only the inscription, but also the participation and completion results were in fact the highest in all the MOOCs offered by UNED-Abierta and MiríadaX on that occasion. In the MiríadaX MOOC competition, for instance, 18 universities mainly from the Spanish-speaking world offered 58

\footnotetext{
${ }^{3}$ The title of the course was "Empieza con el inglés: aprende las 1000 palabras más usadas y sus posibilidades comunicativas" which can be translated as "A Beginners' English Course: Learn the 1000 most frequent words in English and their possibilities for communication".
} 
courses that together had 305,035 inscriptions in all areas of interest. The completion rate of these courses was $13.47 \%$ and some courses had a completion rate close to $40 \%$ (for more detail see https://www.miriadax.net). Having the most popular course and having obtained attainment rates $25.15 \%$ higher than average, encouraged us to analyse the experiences of both designing and putting into practice the MOOC. An online questionnaire was distributed among course participants to get demographic information as well as data regarding their user and learner experiences, and the qualitative information gathered was useful for improving some aspects of the MOOC for its second edition to come in November 2013. The data collection procedure and questionnaires were also tested with this pilot study. This first questionnaire was answered by 840 course participants. $66 \%$ were aged between 30 and $50.68 \%$ were women and $36 \%$ of the total had completed their secondary education, while $55 \%$ had completed higher education. With regard to the qualitative analysis, some very positive comments and ideas regarding the teaching methodology and course organisation were attested, and most course participants reported a positive and fruitful experience with the MOOC, and a willingness to find new courses of the same type (Chacón-Beltrán, 2014).

\subsection{Main Study}

On the occasion of second edition of this MOOC in UNED-Abierta, Beginners' English Course for Spanish Speakers, a large scale empirical study was carried out. The aim of the study was divided into three parts. Firstly, we aimed at getting precise demographic information in order to define the personal profile of MOOC participants because as de Waard et al. (2011) suggest, there is a need to go on researching whether MOOC or unofficial learning attracts a type of learner that is not determined by factors such as age, gender, cultural background and to discover more about learners' motivations for taking a MOOC and their reasons for dropping out. Secondly, the study aimed at discovering the learner and user experience of course participants in aspects related to the teaching and learning methodology and contents. Thirdly, we analysed the participants' linguistic achievements with regards to course contents, that is whether they had learned what they were expected to learn in the eight weeks (25 hours work) of the course.

Three research questions were posed related to the three parts of the study:

1. What type, in terms of personal background and interests, of Spanish mother-tongue speakers learning English complete a beginners' language learning MOOC with an emphasis on vocabulary learning and reading?

2. What is the learner and user experience of course participants taking a beginners' language learning MOOC with regard to this teaching methodology, specifically with regard to the course content, including video recordings and printable learning material?

3. What is the MOOC participants' linguistic attainment in relation to course objectives and contents, namely frequent English vocabulary learning and later recognition in short texts? (Linguistic attainment is measured using a vocabulary quiz distributed before and after completing the MOOC). 


\subsubsection{Methodology and procedures}

MOOC participants were first requested to answer an online questionnaire designed to obtain information about their personal, linguistic and educational background. 9,356 participants started the course, $37.96 \%$ male and $61.6 \%$ female. With regard to their age, $63.05 \%$ were between 25 and 45 years old; $17.85 \%$ between 46 and 55; and $6.04 \%$ between 56 and 66. With regard to their nationality and place of residence at the time of taking the MOOC, $80.09 \%$ took the course from Spain, $4.98 \%$ from Colombia, $3.05 \%$ from Mexico, $2.44 \%$ from Argentina, $1.09 \%$ from Costa Rica, $0.99 \%$ from Chile, $0.60 \%$ from the USA, $0.59 \%$ from Venezuela, and other South American countries in a smaller proportion. Interestingly, some other course participants took the courses from countries where Spanish is not an official language, such as Germany, France, Belgium, United Kingdom, Italy, Greece, The Netherlands, Portugal, Brazil and some other more distant countries like Russia, Uzbekistan, Tanzania, Taiwan, Qatar, etc. which seems to indicate a lack of geographic boundaries when taking a MOOC. With regard to their educational background and completed studies, $45.45 \%$ of MOOC participants had completed a university degree, $7.43 \%$ had completed postgraduate studies, $21.40 \%$ were qualified professionals with vocational training studies, $14.12 \%$ had completed high-school or similar, and $7.20 \%$ had completed obligatory secondary education. With regard to their professional background, $38.17 \%$ were employees, $36.38 \%$ were unemployed, $17.43 \%$ were students, $8.02 \%$ were self-employed. In relation to their previous experience with MOOCs, $88.93 \%$ had never tried this type of learning methodology, $6.56 \%$ had completed MOOCs in different learning platforms, $4.51 \%$ had taken other MOOCs on the same platform, namely UNED-Abierta. As far as their motivation for taking the course was concerned, the highest ranked reasons for taking this MOOC were: (a) the topic or area of interest of this course; b) the usefulness of the course for their professional development; (c) a learning methodology that was convenient and allowed distance learning at their own pace, and (d) the prestige of the academic institution offering the course. It is also remarkable that at the time of enrolling $21.41 \%$ of course participants were interested in getting an attainment certificate, offered by the organising teaching institution.

\subsubsection{Results}

The MOOC referred to in this article was started by 9,356 participants who also answered the online questionnaire that provided information about their personal, linguistic and professional background. 2,281 actually completed the evaluation activities in module 6 , the final module, so we could assume they had completed between $90 \%$ and $100 \%$ of the MOOC; that is, about $24.39 \%$ of the participants who began the course, actually finished it. A pre-test and post-test procedure was used in order to check the effectiveness of the MOOC and the teaching methodology employed to teach high-frequency vocabulary in English and the reading techniques to read and understand short texts. There was a pre-test online questionnaire containing a multiple choice format where course participants needed to identify from four options the Spanish word that meant the same as the English word. This pre-test was presented to the MOOC participants as an optional activity at the beginning of the course and this same test was repeated 8 weeks later after the MOOC had been completed. The pre-test and post-test contained the same items to be tested but they varied with regard 
to item order and some distractors. The questionnaire had been previously tested with a group of ten students to check its validity and adequacy. 325 MOOC participants completed both the initial and the final optional test. It was noticed with regard to the scores obtained that all participants either maintained or improved their score in the post-test. It is worth mentioning that on some occasions course participants achieved the maximum score in the pre-test which meant that they were not in fact absolute beginners of English.

Table 1 shows the descriptive statistics of course participants that had fully completed both the pre- and the post-test, the aim was to find out if there were statistical difference in their pre-post test scores.

Table 1. Means and Standard Deviations in pre and post-test

\begin{tabular}{cccccc}
\hline & N & Min & Max & M & SD \\
\hline Pretest & 325 & 2 & 20 & 15.61 & 3.45 \\
Postest & 325 & 9 & 19 & 17.46 & 1.68 \\
\hline
\end{tabular}

As was expected because of the large number of MOOC participants and their diverse linguistic background, it was a rather heterogeneous group. Considering the participants that had completed their pre and post-test $(N=325)$ a mean score of $15.61(S D=3.45$, Range $=2-20)$ was obtained in the pre-test and a $17.46(S D=1.68$, Range=9-19) in the post-test.

In order to have a closer look at the course participants that showed greatest improvements in the pre- and post-tests, two groups were created, Group A containing the 30 participants who had lowest scores in the pre-test, a rank between 0 and 10, and Group B containing the participants scoring a rank between 11 and 15 points, numbering 105 participants.

Table 2. Means and Standard Deviations in pre and post-test of Group A

\begin{tabular}{cccccc}
\hline & N & Min. & Max. & M & SD \\
\hline Pretest & 30 & 2 & 10 & 8.27 & 2.23 \\
Postest & 30 & 9 & 19 & 15.97 & 2.62 \\
\hline
\end{tabular}

In Table 2 we can see how Group A shows $M=8.27(S D=2.23)$ in the pre-test and $M=15.97$ $(S D=2.62)$ in the post-test. According to the results in the Shapiro-Wilk we cannot assume normal distribution ( $W=.76, p<.05$ and $W=.90, p<.05$ for pre and post-test, respectively), something that could be expected given the size of the group of participants.

According to the results of the Wilcoxon signed-rank test, a non-parametrical test for repeated measurements on a single sample, the differences between the pre and post-test scores are statistically significant in Group A $(Z=-4.71, p<.05)$, post-test scores are higher $(M=15.97$, $S D=2.62)$ as compared to the pre-test $(M=8.27, S D=2.23)$. 
Table 3. Wilcoxon signed-rank test comparing pre and post-test in Group A and B

\begin{tabular}{|c|c|c|}
\hline & Grupo A & Grupo B \\
\hline & Postest -Pretest & \\
\hline$Z$ & -4.71 & -8.58 \\
\hline Asymp. Sig.(2-tailed) & .00 & .00 \\
\hline
\end{tabular}

As far as Group B was concerned, the rank of scores in the pre-test was rather small (1115 ) and therefore a non parametric test was applied. Pre-test scores in Group B using the Wilcoxon signed-rank test, were made to check if there were statistically significant differences once the participants had finished their MOOCs. As can be seen in table 4 the mean in the post-test $(M=17.25, S D=1.63)$ is higher than in the pre-test $(M=13.43, S D=1.37)$ and it was statistically significant $(Z=-8.58, p<.05)$.

Table 4. Means and Standard Deviations in pre and post-test of Group B

\begin{tabular}{cccccc}
\hline & N & Min. & Max. & M & SD \\
\hline Pretest & 105 & 11 & 15 & 13.43 & 1.37 \\
Postest & 105 & 11 & 19 & 17.25 & 1.63 \\
\hline
\end{tabular}

With regard to course participants' comments on the course, they showed a high degree of satisfaction with the course content and methodology, although it should be mentioned that some suggestions for improvement were made. Course designers analysed and implemented them for coming editions. It was perceived that very often course participants did not feel comfortable with the fact that they had to assess other participants' work, or with the assessment that had been made of their own work. They suggested that the rubric procedures adopted was often insufficient to evaluate other partners' pieces of work and provide personalised feedback. Another aspect mentioned before but which is worth analysing is that although the MOOC was designed for absolute beginners it was actually completed by many false beginners, i.e. students that had previous knowledge of English and were not the target audience of the course. A high number of MOOC participants had previous knowledge of English but thought that this MOOC would give them a chance to "refresh" their English. In this respect, some work groups were created in the virtual course for some members who were willing to share resources and contrast their advances with English.

\section{Conclusions}

In relation to the first research question, the data analysed in the previous section allows us to conclude that MOOCs are a teaching and learning methodology that can be adapted to all educational levels, fields of study, ages and geographical areas of the world. In relation 
to the second research question, this learning experience was in general positive for most course participants who expressed gratitude to the course organisers and the institutions that organised the MOOCs for offering this learning opportunity at no cost to the students. Some course participants, however were more critical and provided useful feedback for improving further editions of the MOOC, these suggestions for improvement being mainly related to technical aspects of the platform or minor aspects related to activity accomplishment rather than methodological aspects of MOOCs or course design. The third research question is answered affirmatively as considerable improvement or learning was perceived in the groups of subjects that had completed the MOOC and had also taken a pre-test and a post-test. Some other groups of students performed well in the pre-test and in theory they would not have needed to take the course but in spite of that, they did take it as a refreshment or recycling course and took good advantage of it. These subjects did not experience big improvements in relation to their pre-test and post-test but instead perhaps maintained their knowledge of English and benefited from the strategies taught in the MOOC to continue learning English vocabulary on their own. The interaction with other students of the same level was often valuable as they exchanged Internet resources to keep on learning English after the course. Another consequence of this MOOC was seen in the student forums. Some learning networks were established by participants who started to share Internet resources with other participants with the same language level and the same personal interests. In this sense, social networks between course participants probably continued working after the completion of the MOOC.

Vygotskian methodological principles advocate the "social" nature of learning and its importance for cooperation, interaction and communication of learners in the same social environment (Nassaii \& Swain, 2000). In addition to this, by means of a process of "collective scaffolding" (Lantolf \& Appel, 1994) MOOC participants, and particularly the ones taking this MOOC in English as a Foreign Language for beginners, helped other course participants facilitating development and work on their Zone of Proximal Development (ZPD) (Vygotsky, 1978) as they worked with other students with higher linguistic knowledge in the target language. More recent studies in the field of Foreign Language Learning show how "collective scaffolding" is very useful and provides good results, and allows language learners to be novice learners at the same time as experts within a group ( $\mathrm{Li}, 2013)$. The role of the Vygotskian tradition and cultural psychology have been previously analysed by Clarà \& Barberà (2013).

\section{IMPLICATIONS FOR THE DESIGN OF NEW MOOCS}

Taking the results of this study as a starting point, and the experience gained in three editions of the same MOOC, which have been described in this article, there are some pedagogical implications that can be usefully transferred to other courses at least in the field of Foreign Language Learning, in the belief that one of the main challenges for success lies in learning design (Beaven, Hauck, Comas-Quinn, Lewis, \& de los Arcos, 2014) With regard to crowdsourcing, it was interesting to contrast our experience as MOOC designers with our experience as lecturers in a distance teaching and learning institution, the UNED, the Spanish Distance Teaching and Learning University, where students typically study to get a university degree. We could identify three main differences: (a) in MOOCs, there was 
a "karma" system by means of which students that help other students get badges, prestige and privileges as course participants. This seems to be an interesting way to motivate students to participate positively as they know their opinions or participations can be assessed by others; (b) In MOOCs there were many more students than in our regular university degree courses, a hundred times more, and therefore students' participation in the virtual course were also different; (c) The simplicity of the course; that is, the MOOC was a short language course, with specific objectives, easy to understand, in contrast with degree courses with a final formal evaluation. The three factors favoured the appearance of "superstudents" who took the initiative and continuously helped other students. Three students in particular became very involved on a continuous basis and participated actively to answer questions and solve their course companions' questions and they also encouraged students who had some trouble following the course. In contrast, during the last fourteen years we have been supervising "traditional" virtual courses at the UNED the emergence of such "superstudents" has only occurred twice, and on both occasions there has only been one "superstudent".

Taking into account the experience with the design and implementation of the MOOC described in this article, it can be concluded that having carefully designed teaching/learning materials is possibly the most important factor. Learning materials in MOOCs should be:

a. Transparent. So that students can easily understand what they are expected to do, with clear and precise instructions, and short video recordings.

b. Feasible. Containing activities that are doable, that is, that they do not require additional materials and that they do not create false expectations. In this sense, adequate time planning and the use of scaffolding to facilitate gradual learning is advisable.

c. Motivating. So that students want to do them, agreeable and satisfactory.

d. Worthwhile. So that students perceive the benefits of completing the course for the development of their own English.

e. Open-ended. So that MOOC participants can go on using them even after the course has ended, and they should also include opportunities for self-evaluation.

It is probably the case that not all types of content and all learning levels can be covered with MOOCs but it is true that many people all over the world can benefit from these courses, and that flexible teaching can contribute to social development in many ways, especially in the area of Foreign/Second Language Learning.

The development of such courses is not only probably unstoppable but will also play an important role in the process of deep transformation towards a global type of activity that higher education seems set to experience (Aguaded-Gómez, 2013). Some experts even think that in the near future the presence of MOOCs will directly affect the way teaching institutions will attract, train and pay their teaching staff (Pappano, 2012). Other types of expectations laid on this type of courses are their open nature, without restrictions, that can entail an important contribution for the democratization of access to given knowledge and make it accessible to places where education and training are scarce (Sangrá Morer, 2013).

In general, there is a paucity of studies dedicated to the analysis of the usefulness of MOOCs in terms of learning outcomes. This difficulty is also reinforced by the fact that MOOCs still have only a scarce presence in the area of formal education and therefore we need more studies based on real data provided by real teaching experiences, and perhaps 
fewer opinion-based articles. While there are no quantifiable learning outcomes it will be difficult to develop a teaching/learning theory for the teaching and learning through MOOCs. In the same vein, more descriptive studies on the process of course design and learning experiences, like the ones described in Severance (2013), are needed.

In essence, this study summarizes the experience gained during the design, creation and implementation of a MOOC to recognise and learn the one thousand commonest words in English from a contrastive perspective. The high rate of course participation and completion, and the perceived learning outcomes were noteworthy. In the same way it could be attested that setting and publishing a MOOC is a global activity with far-reaching repercussions all over the world, where the only perceivable limitation is the language used in the MOOC. It was equally clear that there is a global interest for foreign language learning making use of ICT, specifically English.

\section{Acknowledgements}

I would like to thank Jim Lawley, Calum Harvey-Scholes, Esther Reula and UNED-Abierta for their help in the elaboration of this paper and the processing of the data gathered. Any errors or shortcomings are my responsibility alone.

\section{REFERENCES}

Aguaded-Gómez, J.I. (2013). "The MOOC Revolution: A new form of education from the technological paradigm?”, in Comunicar 21: 7-8

Baggaley, J. (2014). "MOOC postscript", in Distance Education 35: 126-132

Beaven, T., M. Hauck, A. Comas-Quinn, T. Lewis, and B. de los Arcos. (2014). "MOOCs: Striking the Right Balance between Facilitation and Self-Determination", in MERLOT Journal of Online Learning and Teaching 10: 31-43.

Benson, P. (1996). "Concepts of autonomy in language learning", in R. Pemberton, E. Li, W. Or, and H. Pierson, 1996 Taking control. Autonomy in language learning. Hong Kong: Hong Kong University Press.

Benson, P. (2007). "Autonomy in language teaching and learning. State of the Art Article", in Language Teaching 40: 21-40.

Benson, P. (2013). Teaching and researching: Autonomy in language learning. Oxon: Routledge.

Chacón-Beltrán, R. (2014). "Massive Online Open Courses and Language Learning: the Case for a Beginners' English Course", in Procedia: Social and Behavioral Sciences 141: 242-246.

Clarà, M., and E. Barberà, E. (2013). "Learning online: Massive open online courses (MOOCs), connectivism, and cultural psychology", in Distance Education 34: 129-136.

Cotterall, S. and R. Cohen. (2003). "Scaffolding for second language writers: Producing an academic essay", in ELT Journal 57: 158-166.

Dellarocas, C., and M. Van Alstyne. (2013). "Money models for MOOCs", in Communications of the ACM 56: 25-28.

European Commision. (2012). Eurobarometer, Special. 386. Europeans and their languages. Report.

Lantolf, J. P., and G. Appel (eds.) (1994). Vygotskian approaches to second language research. Westport: Greenwood Publishing Group.

Lawley, J. 2010. "Conspicuous by their Absence: the Infrequency of very Frequent Words in 
some English as a Foreign Language Textbooks", in R. Chacón-Beltrán, et al (eds) 2010 Insights into Non-native Vocabulary Teaching and Learning. Bristol: Multilingual Matters. Lawley, J. and R. Chacón Beltrán. (2009). English Skills for Independent Learners: B2. Cambridge, UK: Cambridge University Pres.

Li, M. 2013. "Individual novices and collective experts: Collective scaffolding in wiki-based small group writing", in System 41: 752-769.

Mackness, J., S. Mak, and R. Williams. (2010). "The ideals and reality of participating in a MOOC", in Networked Learning Conference 266-275.

Morrison, B.R. (2014). "Self-directed language learning", in English Teaching Professional 92: 4-7.

Nassaii, H. and M. Swain. (2000). "A Vygotskian perspective on corrective feedback: The effect of random versus negotiated help on the learning of English articles", in Language Awareness 9: 34-51.

Paldy, L.G. (2013). "MOOCs in Your Future", in Journal of College Science Teaching 42: 6-7. Pappano, L. (2012). "The year of the MOOC", in The New York Times 2, 2012.

Sangrá Morer, A. (March 4th, 2013). “MOOCmanía? (1)”, in El País. Retrieved from http:// sociedad.elpais.com/sociedad/2013/02/28/actualidad/1362067120_992712.html

Sangrá Morer, A. March (17th, 2013b). ¿MOOCmanía? (3), in El Paî́s. Retrieved from http:// sociedad.elpais.com/sociedad/2013/03/17/actualidad/1363544697_803500.html

Severance, C. (2013). "MOOCs: An Insider's View", in Computer 46: 93-96.

Tinmaz, H. (2012). "Social networking websites as an innovative framework for connectivism", in Contemporary Educational Technology 3: 234-245.

Voller, P., and P. Benson (eds) (1997). Autonomy and independence in language learning. London: Longman.

Vygotsky, L. S. (1995). Mind in society. 1978. Cambridge, MA: Harvard University Press.

de Waard, I., A. Koutropoulos, N. Özdamar Keskin, S. C. Abajian, R. Hogue, C. Rodriguez, et al. (2011). "Exploring the MOOC format as a pedagogical approach for mLearning", in Proceedings from mLearn. Beijin, China. 